\title{
An Examination of the Gender Experiences in Conflict Management Among Communities in Tana River County, Kenya
}

\author{
Jackson M. Manthi (PhD Candidate) \\ Masinde Muliro University of Science and Technology \\ Department of Peace and Conflict Studies, P.O. Box 190-50100 Kakamega, Kenya \\ Silvia K. Vundi, $\mathrm{PhD}$ \\ State Department of Devolution, Ministry of Devolution and ASAL \\ P.O. Box 30004-0100 Nairobi, Kenya \\ Wycliffe Oboka, $\mathrm{PhD}$ \\ Department of Disaster Management and Community Development, \\ the Cooperative University of Kenya
}

\begin{abstract}
Increasing conflicts in many parts of the world are responsible for many losses of lives and destruction to property. Men and women have been cited as experiencing conflicts in unique, diverse and dissimilar ways. In Tana River County of Kenya, conflicts have persistently occurred among the communities with no durable solutions. The study specifically examined the gender experiences in conflict management among communities in Tana River County. The study was guided by the social conflict theory. The study adopted descriptive research design. The target population was male and female heads of households; managers of NonGovernmental Organizations (NGOs); managers of Community Based Organizations (CBOs); youths and, administrative chiefs. The sample size was 384 comprising of 182 female and 202 male heads of households and 22 key informants selected randomly from NGOs, CBOs and area administrative units. The study used both probability and non-probability sampling techniques to select participants who responded to questionnaires, interview and focus group discussions. The study employed both qualitative and quantitative data analysis and presentation was done using frequencies, tables and charts. The study found out the experiences of men and women in conflict management are different. Men's experiences are more on inadequate skills, hostility and difficulty in being trusted to handle conflicts fairly. Women on the other hand have experiences ranging from marginalization, discrimination and gender based violence to unguaranteed security during conflict. The study concludes that the differences in experiences have a potential to influence conflict management. The study recommends that the processes of conflict management should be cognizant of the fact that men and women experience conflicts differently. In order to reduce the conflicts, the managers of conflict among communities in Tana

River county should take into account the differences in order to develop interventions that can reduce conflicts in the communities. (297 words)
\end{abstract}

Keywords: gender experiences, gender differences, conflict management

DOI: $10.7176 / \mathrm{JEP} / 10-27-13$

Publication date:September $30^{\text {th }} 2019$

\subsection{INTRODUCTION}

\subsection{Background to the Study}

The global state of conflicts and failed peace building processes is alarming. In the last few decades, effects of conflicts have been felt in huge losses of lives, destruction of property and displacement of persons as indicated by Goldstein and Pavehouse (2018). The United Nations High Commission for Refugees (UNHCR) survey on worldwide displacements of persons due to conflict and violence related issues revealed that the highest levels of human displacements had been reached by the end of 2017 with staggering figures of 65.6 million compared to 51.2 million in 2014 and 37.5 million a decade ago and the situation was feared to worsen with time (UNHCR, 2018). According to the Armed Conflict Survey done by the International Institute for Strategic Studies (IISS), the World Bank estimated that around 2 billion people, which is about a quarter (1/4) of the world's population, had been affected by some form of conflict and insecurity by the year 2017 (IISS, 2018).

A study done by Oxford University between 2015 to 2016 focusing on the changing character of conflict in the 21 st century done in countries in the global South found out that the conflict situation was increasingly worsening (Oxford University, 2016). This was due to the shift in actors of warfare where the state was ceasing from being the principal actor in the wake of non-state groups who were beginning to take over the conflict situation. Sivard (2012) observes that these non-state groups and individual actors are spread across many parts of the world. They include: militia-groups; intolerant politicians and groups of people opposed to government 
regimes; and communities competing over scarce resources.

The Africa continent has for many years played host to numerous conflicts happening among communities. Southern Sudan's long civil war has claimed over 2.5 million people (UNMISS Human Rights Report, 2014), the Rwanda Genocide left over 1 million people dead (Sambou, 2016). Besides, the Democratic Republic of Congo has been embroiled in inter-community conflicts that ended in hundreds of deaths, thousands of women rapes and millions of people displaced and fleeing their homes as averred by Kavanagh (2010). Kenya like most Sub-Saharan countries has been enmeshed in community conflicts whose origins are traceable back to the colonial administration (Kenya Red Cross Report, 2014). However, Kenya's worst experience is the 2007/8 Post Election Violence (PEV) that claimed over 1000 lives and 600,000 people displaced. Kenya has since then witnessed unparalleled spiral of conflicts in her history (UN Office for Co-ordination of Humanitarian Affairs, 2016).

According to Rummel (2010), this turbulent conflict scenario continues to present varied challenges for men and women in handling conflict for peace building. The situation is further exacerbated by the manner in which the society describes and assigns gender roles to men and women in conflict handling and peace building (Klare, 2010). Gender aspects in conflict management such as; experiences of men and women in management handling, differences in styles men and women prefer to use in conflict management; and how each category of gender is perceived by the society, have a potential to make subsequent peace building processes either a success or an uphill task. This study undertook to examine gender experiences in conflicts among communities in Tana River County.

\subsection{Statement of the Problem}

Inter-ethnic conflicts in Tana River County have been a reoccurring problem for a long time with no durable solution (Kenya Inter-Agency Rapid Assessment, 2015). Sporadic conflicts between the major communities in Tana River County namely, Pokomo and the Orma, date back to the $17^{\text {th }}$ Century and took place mainly during the dry seasons. Goldsmith (2012) observes that, the conflicts have increased in frequency and intensity over the years. In a span of less than six months in 2012/2013, for example, unresolved conflicts claimed over 150 lives while 112,000 persons were displaced and over 700 animals were raided (Kenya Red Cross, 2013). The conflicts have also become more complex with the entry of new and numerous actors. The actors have come into the conflict enterprise with multifaceted motives which have aggravated conflict in the area making peace building efforts more difficult and the conflict handling more complicated as observed by Guyo (2009) and Weiss, (2012).

Conflicts of the kind experienced in Tana River County contribute to: social breakdown; reduction of peoples' quality of life; and loss of lives and property. If appropriate approaches to peace building were adopted, this would promote reconciliation; prevent relapse to conflict and contribute to harmonious living which is good for sustainable development. The experience of men and women during conflicts are different. This uniqueness implies that each has a different contribution to reduce conflicts in the world. The current study considered the need to understand the gender experiences in conflict management as crucial to developing lasting intervention strategies to address conflicts.

\subsection{Objective of the Study}

The specific objective of the study was to examine gender experiences in conflict management among communities in Tana River County, Kenya.

\subsection{LITERATURE REVIEW}

The experiences of men and women in conflict management are unique and different as observed by Kofi in his report on women, peace and security submitted to the United Nations (UN) pursuant to the October, 2000 United Nations Resolution 1325 (Kofi, 2012). This study examines the different ways in which men and women experience conflict in Tana River County.

Hostility is one such experience. Ellonen (2014) defines hostility as a gesture of hatred and unfriendliness emanating from deep seated ill-will between opposing parties and has a potential to make it difficult for warring parties to initiate discussions to end conflicts for peace. Marginalization is another experience in conflicts. It refers to a process where a group of people, normally a minority group, is pushed to the edge of the society and not allowed to have active voice in the running of affairs that affect them (Stearns, 2012). Closely linked to marginalization is gender bias which, as Birkhoff (2017) observes entails unequal treatment in access of opportunities and privileges due to attitudes based on the sex of an individual. Gender biases are witnessed almost in all human setups, whether at the workplace, religious places, or community service giving opportunities (Wallen, 2015).

Having inadequate skills also influences people's experiences in conflict management. People are likely to use inappropriate ways of managing conflicts that exacerbate the conflict situation instead of helping to deal with it (Brinkman \& Hendrix, 2011)). During conflict management, men and women can experience intimidation. 
Omully (2017) avers that, intimidation is manifest through scares and threats so that people do not actively participate in matters affecting them and others. Katie and Galins (2017) argue that intimidations through threats have the potential to stall conflict handling efforts and worsen the conflict situation. Lack of trust is also likely to be an experience in conflict management. Anderson (2013) refers to mistrust as absence of one party's confidence in the other party's ability to do things right as well as live up to the tenets of the promises agreed on hence making it difficult to initiate conflict management processes. The study sought to examine the prevalence of these experiences among men and women in the in the communities in Tana River County.

\subsection{Social Conflict Theory}

The study adopted social conflict theory by Karl Marx (1818-1883). The main tenet of this theory is that the society's dominant and subordinate groups engage in unending power struggles in order to maintain control over specific resources and means of production (Bartos \& Wehr, 2013). This assertion relates to the gender context in Tana River County where the dominant patriarchal structures seem to legitimize marginalization of the subordinate women. The scenario presupposes differences in the experiences of men and women in conflict management.

\subsection{RESEARCH METHODOLOGY}

The study adopted descriptive survey research design. Shields and Rangarjan (2013) observe that descriptive survey design describes the characteristics of a phenomenon as they naturally occur without changing or manipulating them. Through the design, information was obtained using questionnaires and interviews and Focus Group Discussions (FGDs). The study population comprised of 202 male and 182 female heads of households as well as key informants drawn from managers of community based organizations (CBOs); managers of non-governmental organizations (NGOs); and administrative Chiefs. There were 7 FGDs drawn from the youth, women, and village elders, each with 10 participants.

The study adopted multi-stage sampling strategy. Trochim (2012) argues that in multi-stage sampling, the entire population is divided into naturally occurring clusters and sub-clusters from which the study selects the sample. This study had seven cluster stages in sampling. These were: sub-counties; locations; villages; households; heads of households; managers of NGOs; and, managers of CBOs. The study employed both probability and non-probability strategies to select the respondents. In probability sampling, samples are randomly selected in such a way that each unit has an equal chance of being selected as argued by Kerlinger and Lee (2011). Non-probability sampling technique does not use random selection of units but selection is rather done based on subjective judgment of the researcher and it is useful in cases where random probability technique may not adequately yield the desired results (Orodho, 2010).

The study used both qualitative and quantitative approaches in data analysis. Qualitative data was coded and grouped into meaningful and relevant themes, categories and patterns as guided by orderliness (Gibbs, 2009). Descriptive statistics was used to summarize quantitative data and find patterns. Variables were described using characteristics distribution frequency ranges and percentages. Data was interpreted and presented using frequency graphs, tables, charts and percentages.

\subsection{Results and Discussion}

The study sought to establish the views of the respondents on gender experiences in conflict management. The discussion was done under the following sub-headings: hostility, marginalization, improper skills, gender bias, intimidation and lack of trust.

\section{2 Hostility in conflict management}

The study sought to find out whether the respondents perceived hostility as an experience which men and women went through when managing conflict. Their views are shown in Figure 4.1 


\section{Hostility in conflict management}

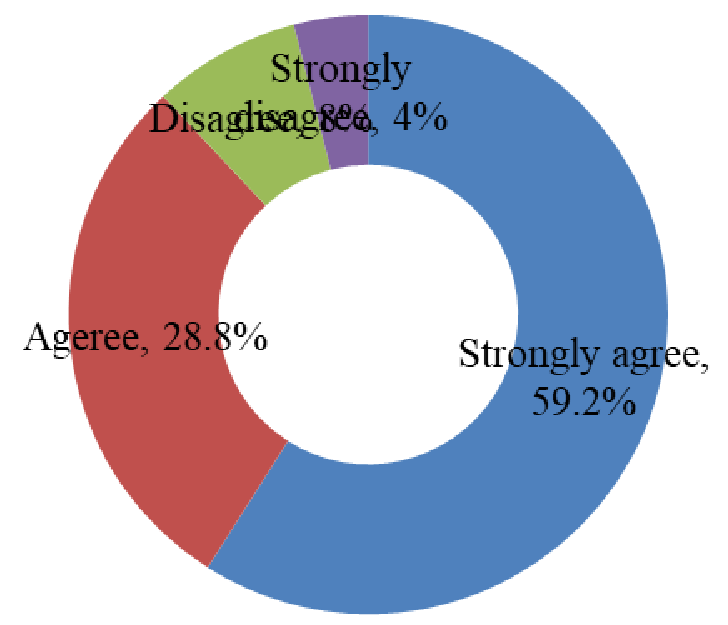

- Strongly agree

Ageree

Disagree

- Strongly disagree

Source: Researcher (2018)

Fig. 4.1 Hostility in conflict management

Figure 4.1 shows a total of $333(88 \%)$ respondents stating that men and women experienced hostility in conflict management. This means that there was deep seated hatred between the communities which has a potential to affect conflict management processes and delay the much desired end to cyclic conflicts the County.

The youth FGDs underlined hostility as a major hindrance experienced by men and women in conflict management. When asked to discuss the experiences men and women went through in conflict management, they confessed that the main communities in Tana River County, Pokomo and Orma, had harbored salient hatred for many years. They argued that this hatred played host to the obvious unfriendly gestures every time conflict erupted, thus, making conflict difficult to manage in order to bring peace. The views from the youth FGDs reveals that hostility as experienced by men and women in conflict management poses a big challenge to conflict management. Hostility can contribute to creating difficult environment for communities to manage their conflicts. This is in tandem with what Ellonen (2014) who observed that, when managing community conflicts among healthcare services beneficiaries in Finland, hostility was a major contributor to lack of breakthrough in bringing the conflicting parties together for peace talks.

\subsection{Marginalization in conflict management}

The study used the scenario of being ignored and pushed to the margins to imply marginalization. It thus sought to find out the views of the respondents on whether women had been ignored and pushed to the margins in the process of conflict management. Nigam (2014) argues that, pushing of one gender to the margins can negatively influence the conflict management processes. The findings are shown in Figure 4.2. 


\section{Marginalization in conflict management}

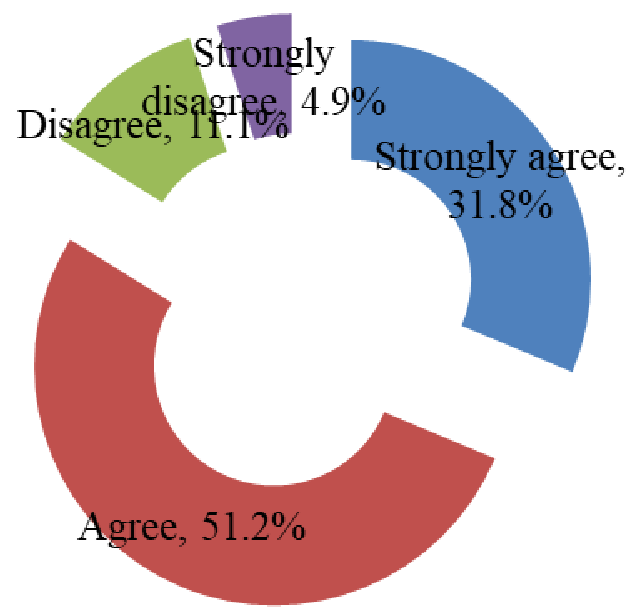

Strongly agree

Agree

Disagree

- Strongly disagree

Source: Researcher (2018)

Fig. 4.2 Marginalization in conflict management

Figure 4.2 shows that $319(83 \%)$ respondents strongly agreed that women had been pushed to the margins while $61(16 \%)$ disagreed. The majority views indicate strongly that men and women in Tana River County experienced marginalization in conflict management. Being pushed to the margins indicates that women cannot make meaningful contribution to the management of conflicts that affect their lives and well-being.

The study presents that marginalization is a major issue to deal with in the processes of conflict management in the County. This position is in line with the views of the administrative chiefs who asserted that men and women had been marginalized in conflict handling processes. Further, they consented that while there may have been few cases where men were marginalized, it was indeed the women who were pushed more to the fringes. Culture and religion were said to be responsible for creating a system where men are valued more than women during conflict management and peace building undertakings. One local chief said:

Our culture gives men an automatic upper hand over the women. The culture values men more than

it does to the women. Pushing women to the margins and not minding so much what value their contribution can bring to conflict management is something that does not seem to bother the men neither does it bother our culture. This situation disadvantages the women in conflict management who do not have to speak when the men are there. The men seem not to have any problem with this

since they are socialized to keep women at the backyard in matters of decision making (Field data, 2019).

Besides, the issue of marginalization was further interrogated from the women FGDs. The women felt that marginalization was not so much an issue that affected the men as it did affect them. Women had been pushed to the margins and their views, needs and concerns ignored by their male counterparts in the conflict and peace building processes in the County.

The study accentuates that women in Tana River County experience marginalization in conflict management. This finding corresponds with the submissions of Goldstein (2010) who averred that marginalization inhibited women from participating in conflict handling because they were forced to assume a backyard position while their male counterparts dominated and took charge of the activities.

\subsection{Gender bias in conflict management}

The study sought to find out whether gender bias was viewed by the respondents as an experience of men and women in conflict handling. Respondents were asked to state whether they perceived men and women to have been treated equally in conflict handling. Figure 4.3 summarizes the findings. 


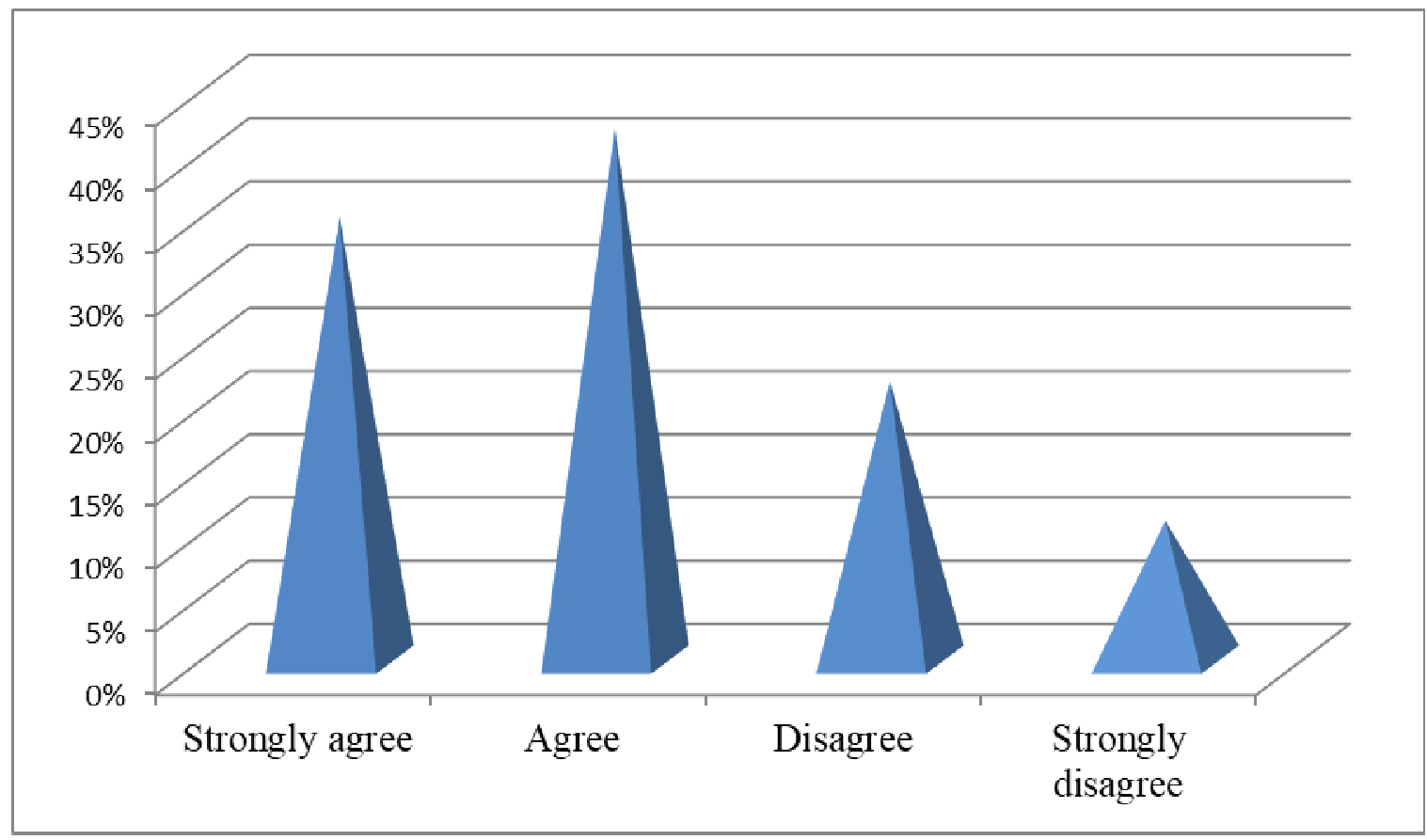

Source: Researcher (2018)

\section{Fig. 4.3 Gender bias in conflict management}

Figure 4.3 illustrates that $295(77 \%)$ respondents strongly agreed that there was unequal treatment of men and women in conflict handling in the County while $88(23 \%)$ respondents did not agree. This indicates that majority of the respondents acknowledged that gender bias was an experience of men and women in conflict management.

From women FGDs, the women were candid that gender bias was a reality in matters of handling conflict in the county. They said that women unlike their male counterparts had particularly been given unequal treatment in matters of conflict handling in their communities. They attributed this inequality in treatment to culture and religion which supported a platform for women to be viewed differently from men. Further, a woman would always be seen as a person who had nothing to offer just because being of female and not male. Further, views from the youth FGDs were that women were neglected in conflict management to a point that their voice and contribution were hardly appreciated. One of the young people in the group said:

Women in our communities have been neglected during conflict solving times. Our men have continued to insist that life can go on without the women's contribution in conflict handling. As a young man, I feel this treatment for women by men is not fair because women contribution is vital and necessary given that it is them who suffer most during conflicts. This practice should be brought to an end so that women will not be ignored and life moves on. No, we must come to a point where men allow women to be involved in the processes because they cannot go far without women (Field data, 2019)

From these views, the study gathers that women in Tana River County experienced gender bias during conflict management more than the men. Gender bias where men or women are given unequal treatment based on their sex orientation is an experience that affects women more than men in conflict handling. For example, women in Burudi were treated differently from their male counterparts in conflict management despite the very common understanding that building sustainable peace needed the participation of both men and women (Agbalajobi, 2011).

\subsection{Inadequate skills of men and women in conflict management}

The study sought to find out whether the respondents viewed men and women as having adequate skills in managing conflicts among their communities. The study considered adequacy in skills as key to competence in conflict management; this is crucial to reduction of conflicts. Scott (2017) argues that, conflict has the potential to grow bigger and complicated if mishandled. The findings are shown in Figure 4. 4. 


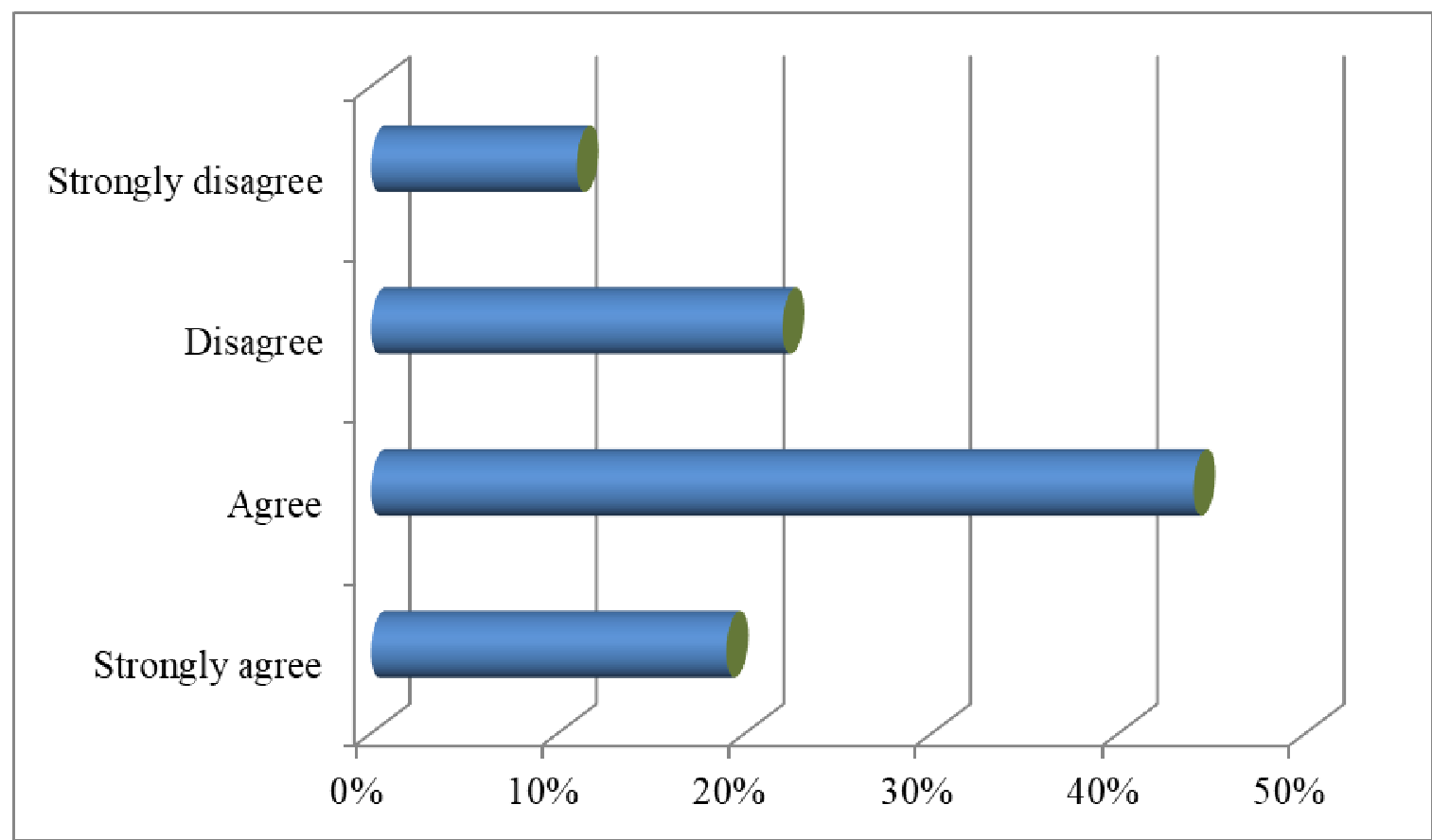

Source: Researcher (2018)

Fig. 4.4 Inadequate skills in conflict management

Figure 4.4 shows that $242(63 \%)$ respondents agreed that men and women did not have adequate skills in conflict handling in Tana River County while 142 (37\%) felt men and women had adequate skills. The findings indicate that majority of the respondents were of the opinion that men and women involved in conflict management in Tana River County had inadequate skills. This means that conflict was likely to be difficult to handle because those who had the opportunity to do so were unskilled. This view corresponds with the submissions of Hicks (2015) in a study on the challenges people face in handling conflict in the place of work. He concluded that, the main challenge of people handling conflict was lack of knowledge in skills to be used and how to use them. The study concludes that there is a great danger when men and women with inadequate skills continue to handle conflicts among communities in Tana River County. There is need to impart the skills to improve on competence.

\subsection{Intimidation of men and women in conflict management}

The study sought to establish whether the respondents perceived that men and women faced intimidation in conflict handling. The study considered intimidation as likely to delimit people's participation in conflict management. Threats of either being killed, hurt or taken through painful experiences in life can scare and limit individual's participation and involvement and making meaningful contributions in conflict management. The findings are shown in Figure 4.5. 


\section{Intimidation}

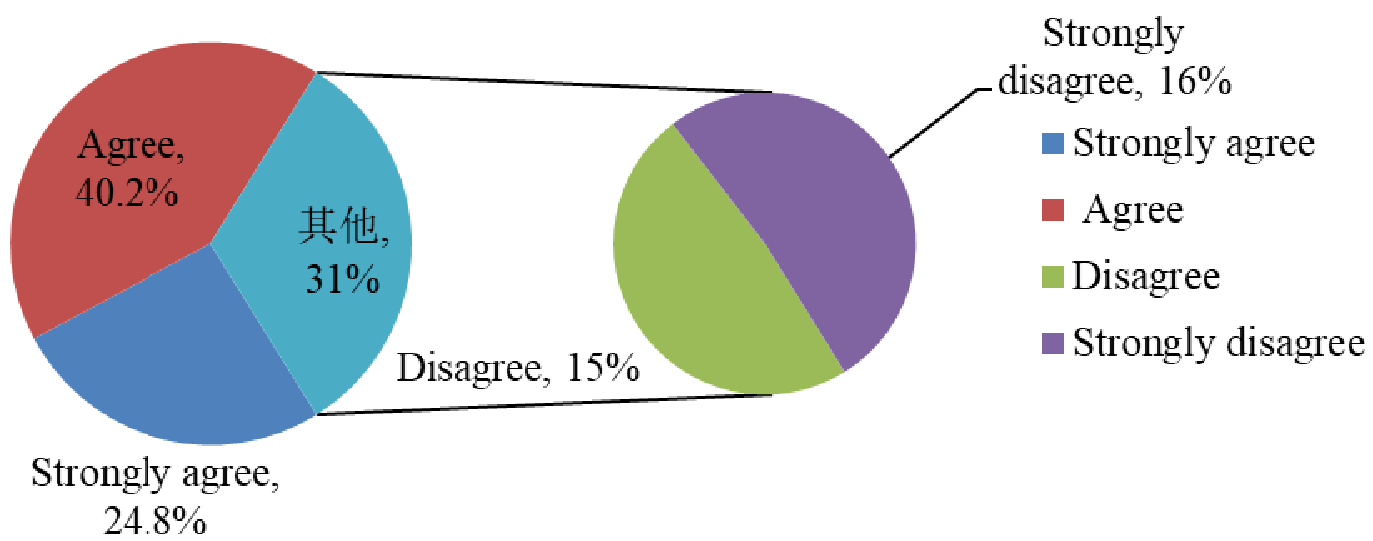

Source: Researcher (2018)

Fig. 4.5 Intimidation in conflict management

Figure 4.5 shows that 249 respondents $(65 \%)$ admitted that men and women faced intimidation in conflict management while 119 (31\%) respondents did not agree. The views of the majority indicated that men and women had been intimidated during conflict management. This implies that men and women had been scared away from fully participating in conflict management processes.

Views from the village elders' during FGDs revealed that intimidation affected women more than men in managing conflict. Women suffered intimidation in at least two areas; one they were scared and threatened by men from rival communities; and two from the men in their own communities. Intimidation of this kind is likely to lead to fewer women than men participating in conflict handling. Katie and Galins (2017) aver that intimidations and threats have the potential to stall conflict handling efforts and instead worsen the conflict situation. Affected parties could retreat to revamp themselves for attacks if threats are not handled well. The study thus advances that handlers of conflict in Tana River County need to find a way of neutralizing threats.

\subsection{Mistrust in conflict management}

The study sought the views of the respondents on whether men and women experienced mistrust in conflict management. The study viewed mistrust as leading people to work in in suspicion and doubts; this hinders conflict management efforts. Figure 4.6 gives the findings. 


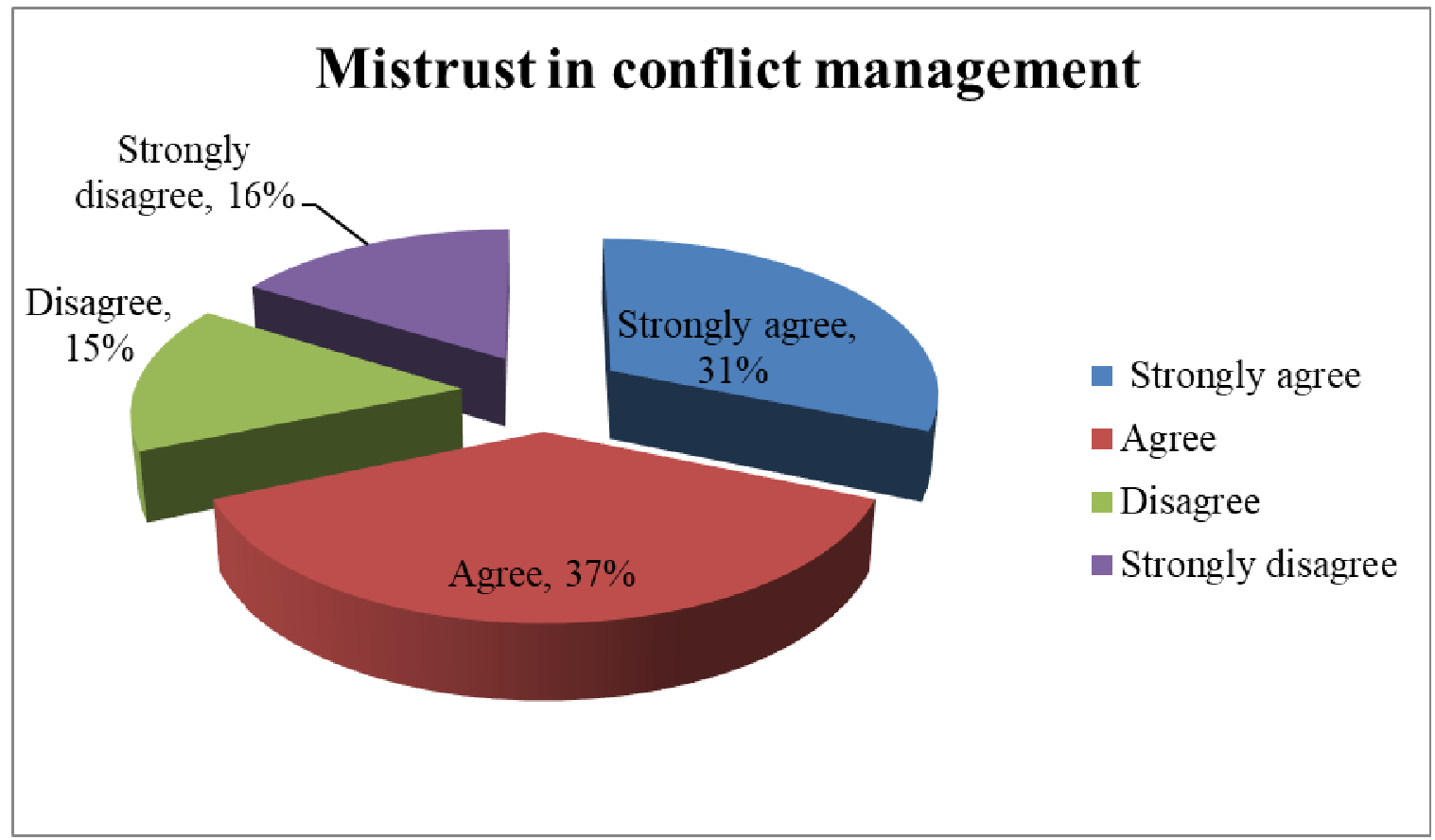

Source: Researcher (2018)

Fig. 4.6. Mistrust in conflict management

Figure 4.6 shows that $261(68 \%)$ respondents agreed that mistrust was an experience that men and women had to contend with in conflict management while $119(31 \%)$ respondents disagreed. These findings indicate that the Pokomo and Orma conflict handlers do not trust that the opposing parties can be relied on to act fairly and justly in matters of conflict management. This position was shared by chiefs who added that mistrust among conflicting parties was aggravated by unfair decisions in conflict management.

The youth FGDs added that lack of goodwill resulting from poor reputation and bad names contributed to mistrust among parties in conflict management. They also asserted that handling conflicts between the Pokomo and the Orma faced the challenge of parties not being accepted or perceived to have leverage required in conflict management.

The study avows that mistrust experienced by men and women has potential to affect conflicts management among communities in Tana River County. This is supported by Wheatley (2012) who avers that continuous acts of taking sides when dealing with conflicts generates mistrust which in turn causes more differences and makes the conflict situation even more complex. There is need for conflict handlers to become aware that taking sides in a conflict situation only creates cycles of conflict as the warring parties continue to seek opportunities for revenge.

\subsection{SUMMARY, CONCLUSIONS AND RECOMMENDATIONS}

\subsection{Summary}

Findings from the six key areas on gender experiences in conflict management among communities in Tana River County showed that: (i) a cumulative 338 (88\%) respondents (Fig. 4.1) stated that men and women experienced hostility; (ii) majority, 319 (83\%) respondents (Fig. 4. 2) stated that men and women had experienced marginalization; (iii) majority, 295 (77\%) respondents (Fig 4.3) admitted gender bias was experienced by men and women: at least 242 (63\%) respondents (Fig. 4.4) acknowledged that conflict managers lacked adequate skills; (iv) among 249 (65\%) respondents, there was admission of men and women having experienced intimidation in conflict management(Fig. 4.5); (vi) majority, $261(68 \%)$ admitted that men and women faced mistrust in conflict management (Fig.4.6).

Further, FGDs clarified the experiences as being more inclined to negatively affecting the woman than the man. Women experiences were more on exclusion in decision making and participation in conflict management because of cultural beliefs and inhibitions.

\subsection{Conclusion}

The experiences of men and women in conflict management are different. Men's experiences are more on inadequate skills, hostility and difficulty in being trusted to handle conflicts fairly. Women on the other hand have experiences ranging from marginalization, discrimination and gender based violence to unguaranteed security during conflict. The differences in experiences have a potential to influence conflict management. 
Managers of conflict among communities in the county should take in to account these differences in order to develop interventions that can reduce conflicts in the communities.

\subsection{Recommendations}

The study recommends that the managers of conflict among communities should take into account the gender differences in conflict management in order to develop interventions that can reduce conflicts in the society. These processes of conflict management should be cognizant of the fact that men and women experience conflicts differently. The intervention should take care of both genders.

\section{REFERENCES}

Anderson, J. (2013). Why Trust is Important in Negotiation. Amazon: The Accidental Newsletter Publishers.

Ellonen, H. (2014). Exploring the Business Perspectives of Hostility in Virtual Communities. Finland: Lappeenranta University of Technology Press.

Gibbs, G. (2009). Analyzing Qualitative Data. Belmont: Wadsworth Publishing Company

Goldsmith, P. (2012). The Tana Delta Clashes Do Not Fit The Farmer Herder Completion For Resources Narrative. The East African, September, 15, 2012.

Goldstein, J., \& Pevehouse, J. (2018). International Conflict. New York: Pearson.

Goldstein, N. (2010). Gender and Marginalization. Washington DC: Center for Global Development.

Guyo, B. (2009). Historical Perspectives on the Role of Women in Peace-Making and Conflict Resolution in Tana River District, Kenya, 1900 to Present. Miami: Miami University press.

Hicks, T. (2015). Seven Steps for Effective Problem Solving in the Workplace. The Business Journal of Sonoma/Mann, 39, 345-452.

International Institute for Strategic Studies (IISS). (2018). The Armed Conflict Survey. Washington DC: International Institute for the Strategic Studies Report, 2015.

Katie, A. \& Galins, A. (2017). How to Defuse Threats at the Bargaining Table. Havard: Havard Law School.

Kavanagah, M. (2010). The Roots of Conflict in Eastern Democratic Republic of Congo. Washington, DC: Pulitzer Center.

Kenya Inter-Agency Rapid Assessment. (2015). Kenya Inter-Agency Rapid Assessment Report.

Kenya Red Cross. (2014). Fresh Violence in Tana River Delta. Nairobi: Kenya Red Cross Report.

Kenya Red Cross. (2014). Fresh Violence in Tana River Delta. Nairobi: Kenya Red Cross Report.

Kerlinger, F. \& Lee, H. (2011). Foundations of Behavioral Research. New York: Harcourt College Publishers.

Klare, M. (2010). Light Weapons Diffusion and Global Violence in Post- Cold War Era. New Delhi: Indian Puwash Society.

Kofi, A. (2012). Responding to Situations of Conflicts. Washington, DC: United Nations Report.

Nigam, S. (2014). The Margins: Revising the Concept of Marginalized Women. New Delhi: Center for Women Development Studies.

Omully, J. (2017). Intimidation: Scaring away the Timid in Order to have Total Control. Lagos: Dorrance Publishers.

Orodho, A. (2010). Essentials of Education and Social Science Research Methods. Nairobi: Masola Publishers.

Oxford University, (2016). Changing Character of War in the $21^{\text {st }}$ Century. Oxford: Oxford University Press.

Rummel. J. (2010). Understanding Conflict and War. Cambridge: Cambridge University Press.

Sambou, J. (2016). Genocide in Rwanda: Understanding why they Died. New York: The City University of New York.

Shields, P. \& Rangarjan, N. (2013). A Playbook of Research Methods. Stillwater: New Forum Press.

Sivard, R. (2012). World Military and Social Expenditures. Washington DC: World Priorities.

Stearns, J. (2012). The Evolution of Armed Movement in Eastern Congo. Nairobi: Rift Valley Institute.

Trochim, W. (2012). Research Methods Research Base. Cincinati: Atomic Dog Publishing.

United Nations High Commission for Refugees, (2018). Global Trends 2015: World at War. Geneva: Switzerland.

United Nations Mission in South Sudan. (2014). Conflict in South Sudan: Human Rights Report.

United Nations Mission in South Sudan. (2014). Conflict in South Sudan: Human Rights Report.

United Nations Office for Co-ordination of Humanitarian Affairs (2016).

Wallen, J. (2015). Gender Biases in the Workplace. New York: Techpro Research.

Weiss, T. (2012). Guns in the Borderlands: Reducing the Demand for Small Arms. Pretoria: Institute for Security Studies.

Wheatley, M (2012). Solving not Attacking Complex Problems. New York: Berkena Press. 